\title{
KINETICS AND MECHANISM OF OXYGEN DESORPTION FROM ANODIZED POLYCRYSTALLINE PLATINUM ELECTRODES UNDER OPEN CIRCUI' IN CARBON MONOXIDE SATURATED $1 M$ PERCHLORIC ACID
}

\author{
S.A. BILMES, N.R. DE TACCONI and A.J. ARVIA
}

Instituto de Investigaciones Fisicoquimicas Téricas y Aplicadas, INIFTA, Casilla de Correo 16, Sucursal 4, 1900 La Plata (Argentina)

\begin{abstract}
The open circuit potential decay of polycrystalline platinum electrodes which were previously anodized in $1 M$ perchloric acid saturated with carbon monoxide is studied. The amount of electroadsorbed oxygen is measured by combining the potential decay measurements with electroreduction voltammograms. The kinetics of the open circuit anode potential decay are interpreted in terms of a Langmuir-Hinshelwood-type mechanism where two simultaneously adsorbed species, namely oxygen atoms and linear carbon monoxide, are involved.
\end{abstract}

\section{INTRODUCTION}

The electrooxidation of carbon monoxide on polycrystalline platinum occurs in a potential range where there is competition for adsorption sites between $\mathrm{CO}, \mathrm{H}_{2} \mathrm{O}$, $\mathrm{OH}$-species and $\mathrm{O}$-adatoms [1-3]. the adsorption of carbon monoxide in acid electrolytes implies the existence of at least two adsorbed structures [2-6] whose relative surface concentrations depend principally on the electrode history and perturbation conditions, and to a lesser extent on the solution composition and temperature. The different mechanisms proposed for the electrochemical oxidation of carbon monoxide on platinum in acid [7-10] admit the simultaneous existence of at least two adsorbed reactants, namely $\mathrm{CO}$ and $\mathrm{O}$-atoms. The potential of platinum under open circuit conditions depends on the electrode surface coverage by these species, which in turn are influenced by the concentration of carbon monoxide and the composition of the electrolyte solution. Hence, it is possible to study the reaction associated with the potential decay of platinum in acid produced by the presence of carbon monoxide, by combining cyclic voltammetry and potential decay measurements.

The O-electroadsorption on platinum in the absence of dissolved oxygen, involves the chemical and electrochemical dissolution of the corresponding surface oxide, as well as ageing processes related to the surface oxide layer. The former occurs under quasi-equilibrium conditions over a relatively wide potential range $[11,12]$ and the dissolution process apparently follows zero order kinetics. The current density 
associated with the process is ca. $1 \mu \mathrm{A} \mathrm{cm} \mathrm{cm}^{-2}$, a value which can be disregarded in conventional voltammetric measurements. Ageing processes play an important role in dealing with the kinetics of the O-electrodesorption as the mean activity of the reactant depends on the whole electrode history. The presence of carbon monoxide considerably influences the O-electrosorption processes on platinum in acid as at least three new interactions appear, namely $\mathrm{Pt}-\mathrm{CO}, \mathrm{Pt}(\mathrm{O})-\mathrm{CO}$ and $\mathrm{Pt}(\mathrm{O})-\mathrm{Pt}(\mathrm{CO})$, where the parenthesis denote species adsorbed on platinum.

The present work refers to the kinetics and mechanism of oxygen desorption from polycrystalline platinum in acid in the presence of carbon monoxide from potential decay of an anodized electrode. The reaction mechanism advanced for interpreting the results is correlated to those previously discussed for both the voltammetric oxidation of carbon monoxide in acid [9] and for the ageing of the O-electroadsorbed monolayer on platinum [11,12].

\section{EXPERIMENTAL}

The experimental setup is the same as already described in a previous publication [9]. Electrochemical data come from both potential transients of the anodized electrode when the anodic current is switched off and from potentiodynamic sweeps in the negative direction starting from a certain value of the open circuit potential $\left(E_{\mathrm{e}}\right)$. The potential of the working electrode is measured against the hydrogen reversible electrode in the same electrolyte. The corresponding complete potential controlled perturbation programs are depicted in the figures described further on. Runs are made at $25^{\circ} \mathrm{C}$ in $1 \mathrm{M} \mathrm{HClO}_{4}$.

\section{RESULTS}

\section{Potential transients under open circuit}

The potential perturbation program consists of the initial triangular potential cycling at $0.1 \mathrm{~V} \mathrm{~s}^{-1}$ between $E_{\mathrm{s}, \mathrm{c}}=0.03 \mathrm{~V}$ and $E_{\mathrm{s}, \mathrm{a}}=1.51 \mathrm{~V}$ followed by the potential holding at $E_{\mathrm{s}, \mathrm{a}}$ during the time $\tau_{\mathrm{p}}$, to achieve a preset ageing of the O-electroadsorbed layer and finally, the current switching off at $E_{\mathrm{s}, \mathrm{a}}$ to record the potential decay (Fig. 1). $\tau_{\mathrm{p}}$ is varied in the $0-30 \mathrm{~s}$ range to start from differently aged O-electroadsorbed layers. The potential of platinum in $1 \mathrm{M} \mathrm{HClO}_{4}$ under nitrogen saturation after the current switching off exhibits a rapid initial decay to attain a pseudo-rest potential at ca. $0.86 \mathrm{~V}$, and then the potential decay curve involves a transition time, $\tau$, which increases according to $\tau_{\mathrm{p}}$. This behaviour approaches that reported for the potential decay of platinum in helium saturated sulphuric acid solution [13]. Within the potential range of the pseudo-rest potential the surface coverage by $\mathrm{O}$-adatoms becomes practically zero. The initial abrupt potential change and that related to the inflexion point in the potential decay are mainly associated with double layer discharging effects. Below $0.35 \mathrm{~V}$, potential changes due to the $\mathrm{H}$-adatom electroadsorption are observed, and finally the corresponding true rest potential value is attained. 


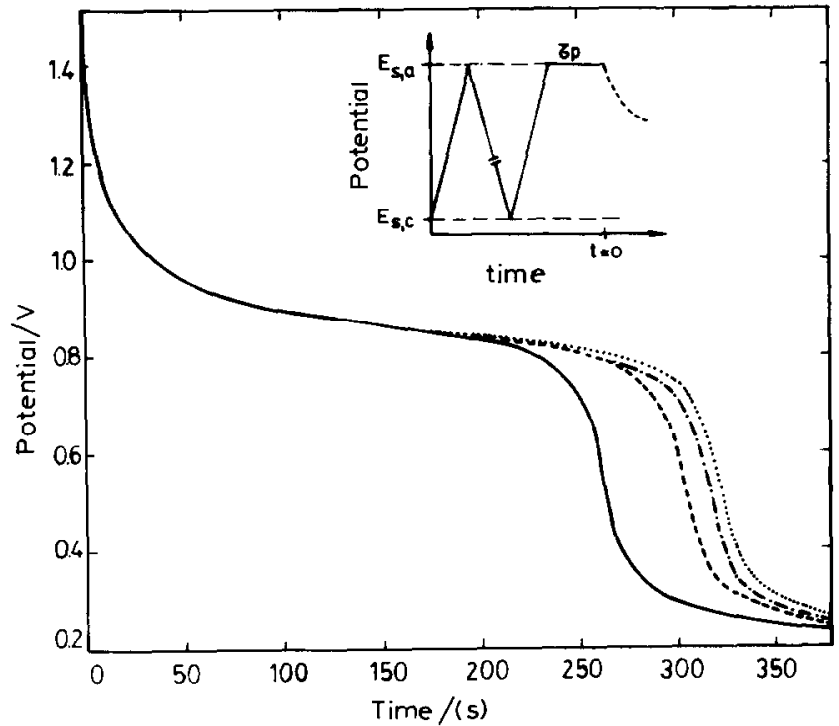

Fig. 1. Potential decay of the polycrystalline platinum electrode in $1 \mathrm{MHClO}_{4}, \mathrm{~N}_{2}(1$ atm). Before the current switch-off the electrode was perturbed with the potential-time program depicted in the figure. $\tau_{\mathrm{p}}=0(-), \tau_{\mathrm{p}}=5 \mathrm{~s}(---), \tau_{\mathrm{p}}=15 \mathrm{~s}(\cdot-\cdot \cdot \cdot)$ and $\tau_{\mathrm{p}}=30 \mathrm{~s}(\cdot \cdots \cdot)$.

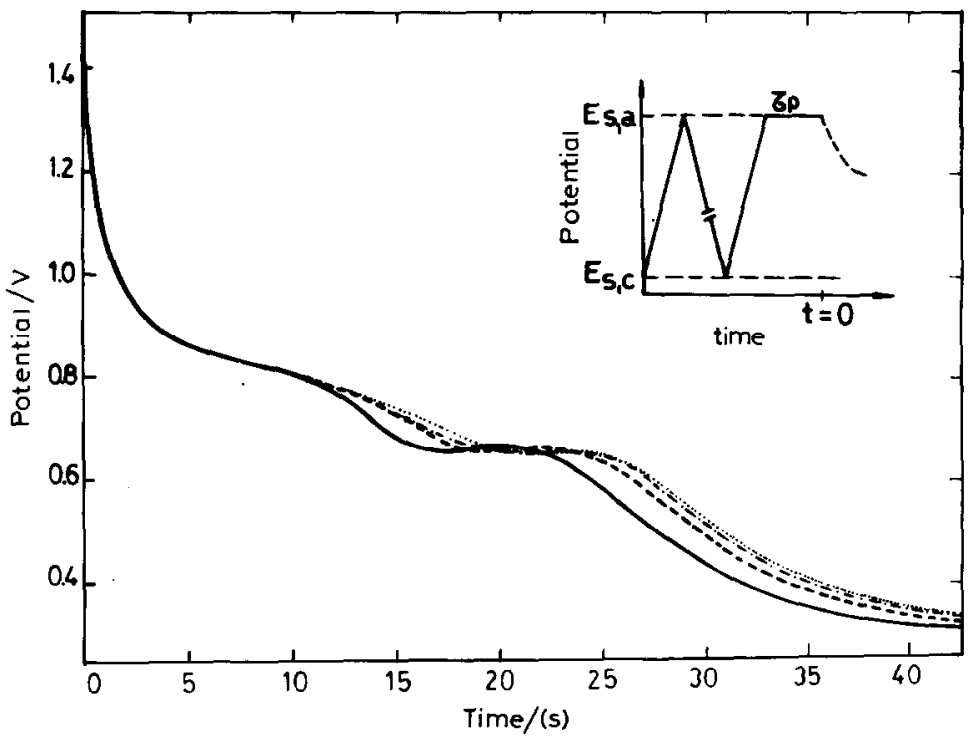

Fig. 2. Potential decay of polycrystalline platinum in $1 \mathrm{M} \mathrm{HClO}$, $\mathrm{CO}$ (1 atm). The experimental conditions are the same as indicated in Fig. 1. 
In the presence of carbon monoxide in the solution the potential decay curve changes drastically (Fig. 2). Thus, the rate of $\mathrm{O}$-adatom surface coverage disappearance increases one order of magnitude as compared to runs made in the absence of carbon monoxide. In this case, there are two potential plateaus, one relatively short at ca. $0.86 \mathrm{~V}$ and another of about the same extension at ca. $0.66 \mathrm{~V}$. Correspondingly, two transition times, $\tau_{1}$ and $\tau_{2}$ can be defined. The potential transient under open circuit depends on the switching potential value $E_{\mathrm{s}}$ (Fig. 3 ). Thus, when $E_{\mathrm{s}}$ is lower than $0.6 \mathrm{~V}$, the potential transient exhibits a maximum, the latter is not observed when the transient is recorded starting at any other potential during the positive going potential scan. These results indicate that the potential at the maximum should be related to the presence of carbon monoxide which is adsorbed on the electrode surface free of electroadsorbed oxygen.

Combined open circuit potential decay and O-electrodesorption under a linear potential scan

By coupling the perturbation program previously described with a negative potential going scan from $E_{\mathrm{e}}$ downwards, it is possible to obtain a voltammetric

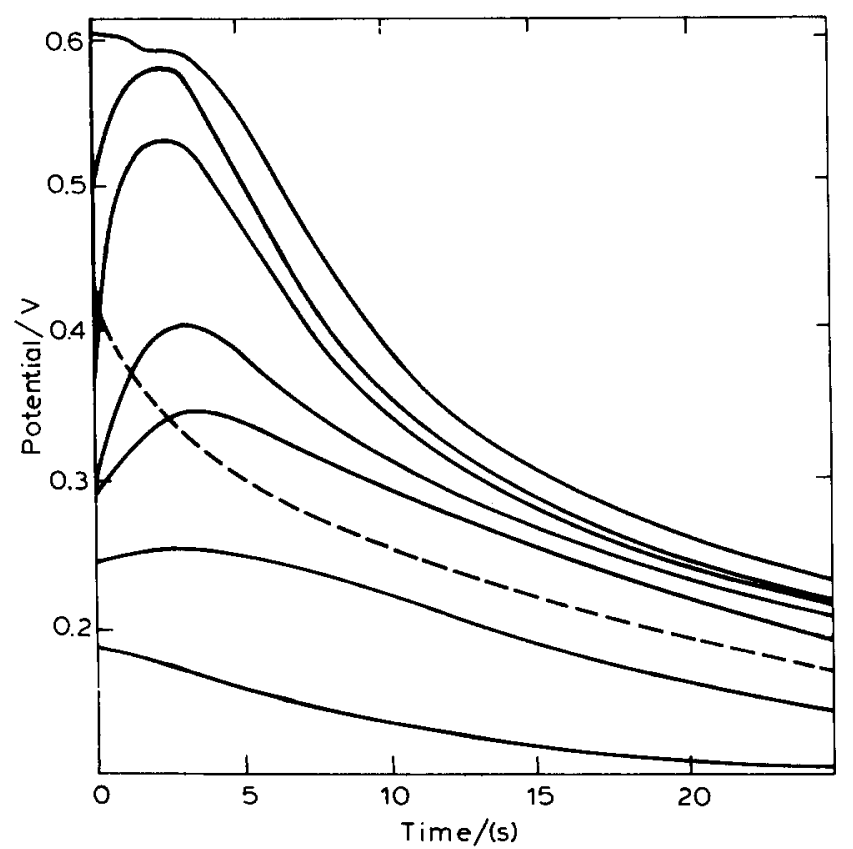

Fig. 3. Evolution of potential for polycrystalline platinum in $1 \mathrm{MHClO}$, $\mathrm{CO}(1 \mathrm{~atm})$, when the current is switched off at different potential values during the cathodic potential scan (full lines) and during the anodic potential scan (dashed line), For each recording the current is switched off when the potential scan reaches the potential value at $t=0$. 
measurement of the O-electroadsorbed charge remaining on the electrode at $E_{\mathrm{e}}$ after the open circuit potential decay. The crucial problem in these experiments is to match the potential for initiating the potentiodynamic sweep exactly to $E_{\mathrm{e}}$ to avoid spurious potential pulses. In the absence of carbon monoxide the resulting voltammograms (Fig. 4) show that as $t_{\mathrm{e}}$ increases, $E_{\mathrm{e}}$ decreases, the O-electrodesorption charge and the corresponding peak potential also decrease due, in part, to ageing effects, and the first $\mathrm{H}$-adatom electroadsorption peak becomes more negative. In this case, the overall $\mathrm{H}$-adatom charge remains practically constant and an isopotential appears at ca. $0.27 \mathrm{~V}$. This effect, which is very possibly produced by anion adsorption, also decreases the $\mathrm{O}$-electroadsorption charge similarly to other noble metals in acid under different adsorption time conditions for anions [14]. The potential holding at $E_{\mathrm{s}, \mathrm{a}}$ produces a slight increase in the O-electroreduction charge and a shift of the corresponding peak potential towards more negative values, as previously reported in relation to the potentiostatic ageing and growth of O-electroadsorbed species on platinum in acid [15].

In the presence of carbon monoxide, results from the application of the combined perturbation program depicted in Fig. 5, show that the $\mathrm{H}$-electrosorption charge is

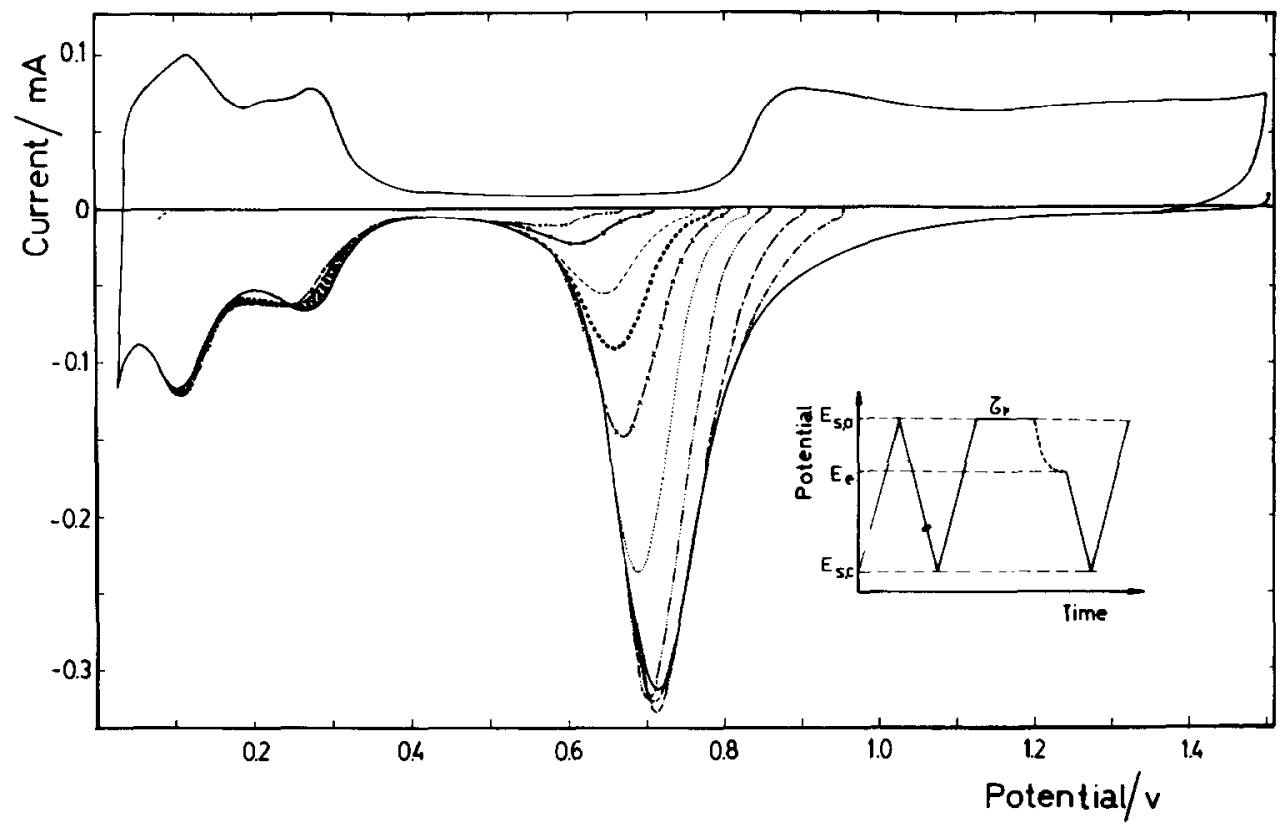

Fig. 4. Voltammograms at $0.1 \mathrm{~V} \mathrm{~s}^{-1}$ for polycrystalline platinum in nitrogen saturated $1 \mathrm{M} \mathrm{HClO}_{4}$ recorded after the open circuit potential change from $E_{\mathrm{s}, \mathrm{a}}$ to $E_{\mathrm{e}}$. Before the current switch-off, the potential is held at $E_{\mathrm{s}, \mathrm{a}}$ during $\tau_{\mathrm{p}}=30 \mathrm{~s}$. The time $\left(t_{\mathrm{e}}\right)$ of the open circuit potential decay was changed as follows: $t_{\mathrm{e}}=0(\longrightarrow), t_{\mathrm{e}}=47 \mathrm{~s}(\cdot-\cdot-\cdot), t_{\mathrm{e}}=72 \mathrm{~s}(---), t_{\mathrm{e}}=113 \mathrm{~s}(-\cdots-), t_{\mathrm{e}}=189 \mathrm{~s}(\cdots \cdots)$, $t_{\mathrm{e}}=245 \mathrm{~s}(-\mathrm{x}-), t_{\mathrm{e}}=274(\bigcirc \bigcirc \bigcirc), t_{\mathrm{e}}=290 \mathrm{~s}(---), t_{\mathrm{e}}=307 \mathrm{~s}\left(-\mathrm{O}_{-}\right)$. 
unaffected when $E_{\mathrm{e}}>0.74 \mathrm{~V}$, but it progressively diminishes when $E_{\mathrm{e}}$ is lower than $0.74 \mathrm{~V}$ and practically disappears when $E_{\mathrm{e}}$ becomes less than $0.65 \mathrm{~V}$, that is, at potentials below which the potential decay curve exhibits a maximum value. These results confirm that in the presence of carbon monoxide no O-electroadsorbed species remain on the electrode, the platinum surface becoming completely covered by adsorbed carbon monoxide which inhibits $\mathrm{H}$-electroadsorption.

The potential transient obtained with an electrode covered with oxygen containing species and previously held at a constant potential during a certain time, $\tau$, in the CO-saturated electrolyte, is considerably different from that resulting in $1 \mathrm{M} \mathrm{HClO}_{4}$. Thus, during the anodic potential step at $E_{\mathrm{s}, \mathrm{a}}$ an appreciable anodic current is recorded and the electroreduction charge resulting afterwards in the negative potential going scan becomes appreciably smaller than that in the blank. These effects at $E_{\text {s.a }}$ are probably related to the continuous formation of the O-electroadsorbed species and its reduction by carbon monoxide.

On the other hand, when the linear potential sweep ranges from $E_{\mathrm{s}, \mathrm{c}}=0.03 \mathrm{~V}$ up to $E_{\mathrm{s}, \mathrm{a}}=1.0 \mathrm{~V}$, at $0.1 \mathrm{~V} \mathrm{~s}^{-1}$, the electrooxidation of carbon monoxide is characterized by a single sharp peak at ca. $0.95 \mathrm{~V}$ [5]. But when $E_{\mathrm{s} . \mathrm{c}}$ is changed to $0.44 \mathrm{~V}$, as the complete O-electrodesorption proceeds, only fractional carbon monoxide surface coverages are accomplished. Hence the corresponding electrooxidation voltammogram exhibits the $i / E$ characteristics previously reported [5] where there are at least two anodic current peaks (I and II) (Fig. 6). Moreover, when the open circuit timc is less than $10 \mathrm{~s}$, no carbon monoxide adsorption is detected, although as $t_{\mathrm{e}}$ increases the amount of $\mathrm{O}$-electroadsorbed decreases and the contribution of peak $\mathbf{I}$

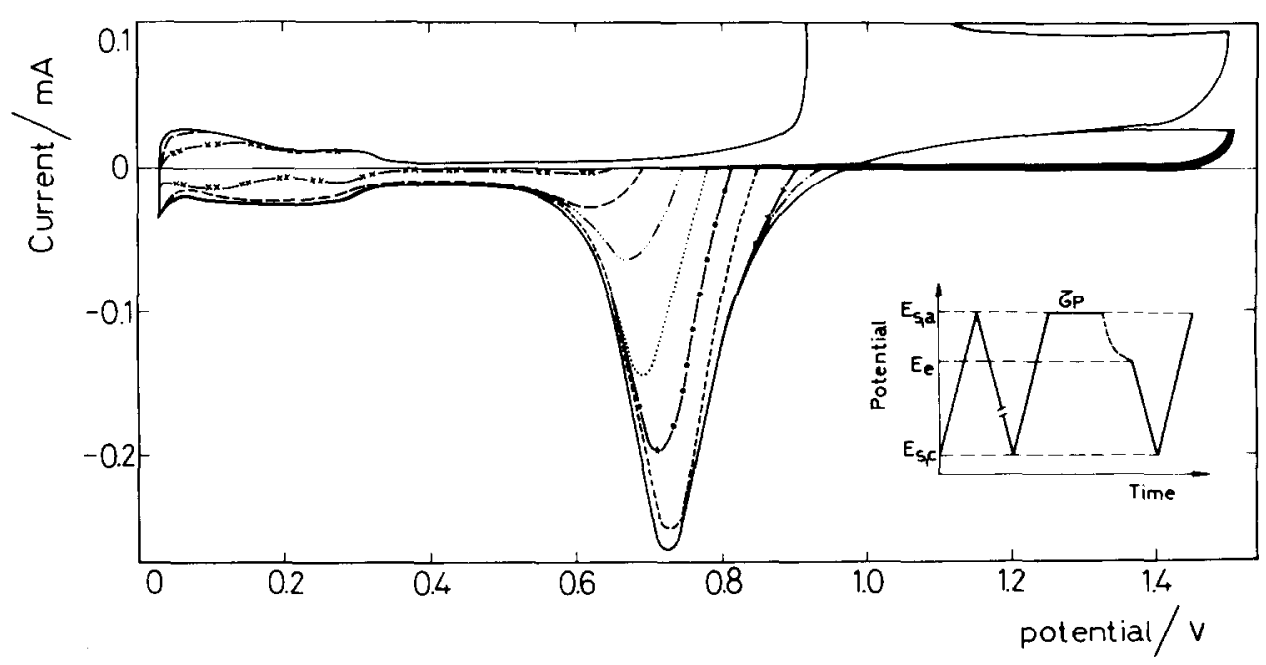

Fig. 5. Voltammograms run in the same conditions as in Fig. 4 for polycrystalline platinum in $1 M$ $\mathrm{HClO}_{4}, \mathrm{CO}(1 \mathrm{~atm}) . t_{\mathrm{e}}=0(-), t_{\mathrm{e}}=1.1 \mathrm{~s}(-\cdot-), t_{\mathrm{e}}=1.5 \mathrm{~s}(-\times-), t_{\mathrm{e}}=4.5 \mathrm{~s}(---), t_{\mathrm{c}}=9.2 \mathrm{~s}$ $\left(-\mathrm{O}_{-}\right), t_{\mathrm{e}}=11.5 \mathrm{~s}(\cdots \cdots), t_{\mathrm{e}}=14.8 \mathrm{~s}(-\cdots-), t_{\mathrm{e}}=18 \mathrm{~s}(---), t_{\mathrm{e}}=22.5(-\times \times-)$. 
also decreases but that of peak II increases. This means that the linear carbon monoxide adsorbed structure related to peak II predominates over the bridged carbon monoxide structure associated with peak I [5,9]. Finally, once the pseudo-rest potential is below ca. $0.66 \mathrm{~V}$, a surface practically free of $\mathrm{O}$-adatoms is available for carbon monoxide. Then, the conventional single sharp carbon monoxide adsorbed electrooxidation peak is recorded.

The reproducibility of charges derived from voltammograms is about $5 \%$. In carbon monoxide saturated electrolyte the potential of the second plateau observed in the potential decay curve fluctuates between $0.64 \mathrm{~V}$ and $0.66 \mathrm{~V}$, and the reproducibility of the time required to reach $E_{\mathrm{e}}$ is about $2 \%$.

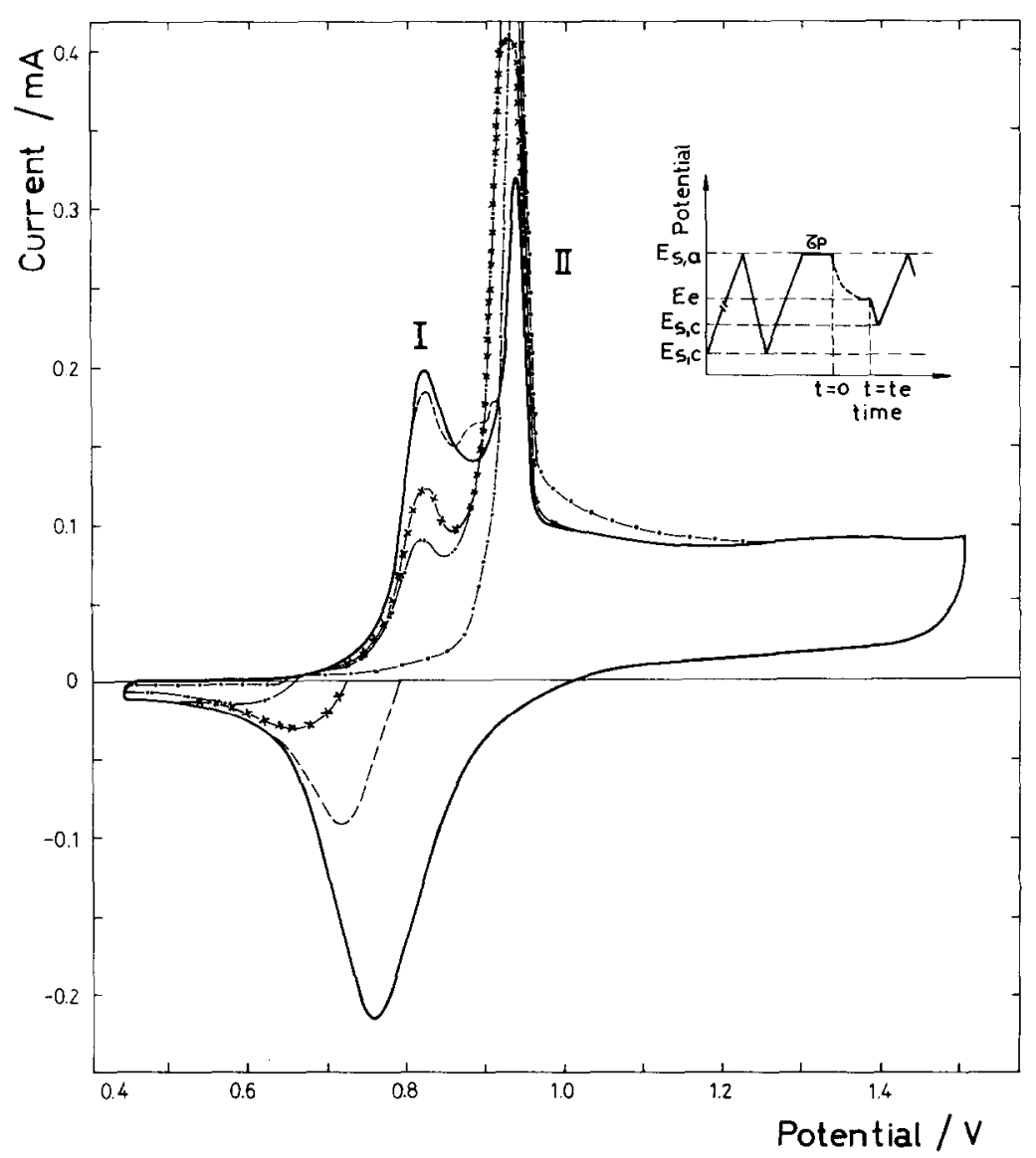

Fig. 6. Potentiodynamic $E / I$ profiles at $0.1 \mathrm{~V} \mathrm{~s}^{-1}$ for polycrystalline platinum in $1 M \mathrm{HClO}_{4}, \mathrm{CO}(1$ atm), resulting from the application of the potential perturbation program shown in the figure. $\tau_{\mathrm{p}}=0$, $E_{\mathrm{s}, \mathrm{a}}=1.51 \mathrm{~V}, E_{\mathrm{s}, \mathrm{c}}^{\prime}=0.44 \mathrm{~V}, E_{\mathrm{s}, \mathrm{c}}=0.02 \mathrm{~V}, t_{\mathrm{e}}=0(-), t_{\mathrm{e}}=10.2 \mathrm{~s}(---), t_{\mathrm{e}}=13.1 \mathrm{~s}(-\times-)$, $t_{\mathrm{e}}=15 \mathrm{~s}(-\cdots-), t_{\mathrm{c}}=20 \mathrm{~s}(-\cdot-)$. 


\section{INTERPRETATION OF RESULTS}

The degree of surface coverage by the O-electroadsorbed species, namely $\mathrm{Pt}(\mathrm{OH})$, $\operatorname{Pt}(\mathrm{O})$ and their corresponding aged forms, $\left(\theta_{0}\right)$, is defined as follows

$\theta_{\mathrm{O}}=Q_{\mathrm{c}} / 2 Q_{\mathrm{H}}$

$Q_{\mathrm{c}}$ is the voltammetric electroreduction charge of the $\mathrm{O}$-species remaining on the electrode surface after the current is switched off, and $Q_{1 I}$ is the charge related to the electroformation of the $\mathbf{H}$-adatom monolayer on polycrystalline platinum [16], evaluated from the voltammogram run at $0.1 \mathrm{~V} \mathrm{~s}^{-1}$ and $t_{\mathrm{e}}=0$ in carbon monoxide free electrolyte. The latter is corrected for the double layer charge.

The value of $\theta_{\mathrm{O}}$ depends on $t_{\mathrm{c}}, \tau_{\mathrm{p}}$, and the electrolyte composition (Fig. 7). Otherwise, the dependence of $\theta_{\mathrm{O}}$ on potential is qualitatively similar for both the blank and the carbon monoxide containing electrolyte (Fig. 8), although for the latter a lower limiting coverage by $\mathrm{O}$-electroadsorbed species is reached. The reverse result is, however, observed at low potentials.

\section{DISCUSSION}

During the open circuit potential decay of anodized platinum in acid in the presence of carbon monoxide, the changes in surface coverage correspond to changes in the total electrode pseudocapacitance. In this case, a potential arrest in the decay

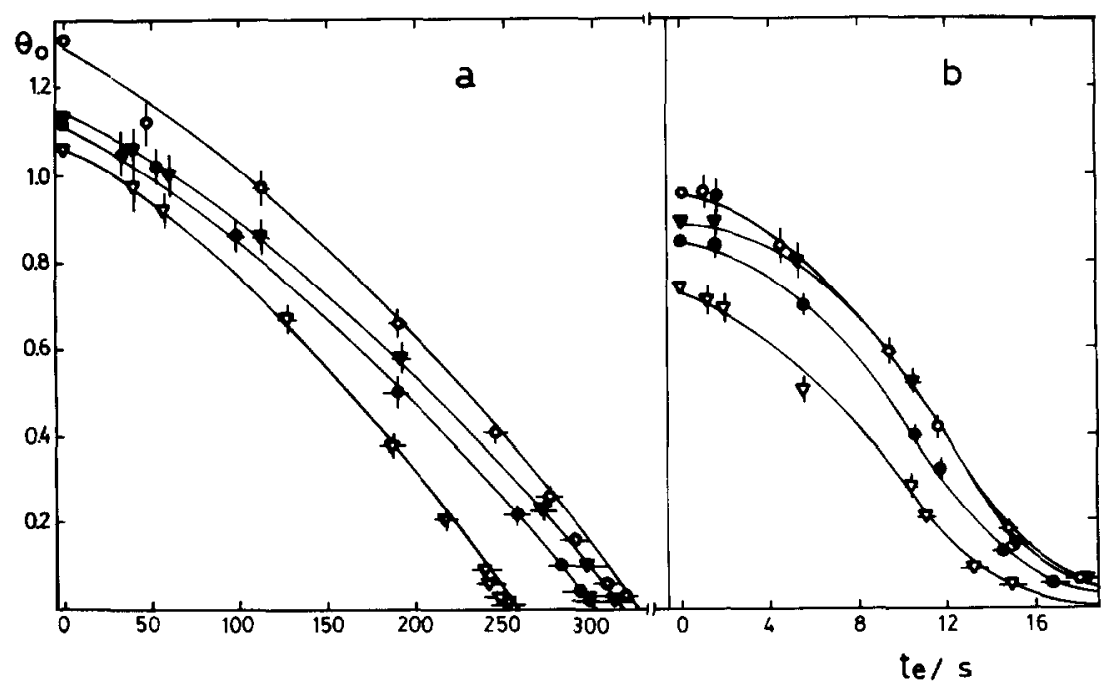

Fig. 7. Dependence of $\theta_{0}$ on $t_{\mathrm{e}}$ derived from the potentiodynamic profiles as in Figs. 4 and 5 . (a) $N_{2}$ saturated, (b) CO saturated. $\tau_{p}=0(\nabla), \tau_{p}=5 \mathrm{~s}(\bullet), \tau_{p}=15 \mathrm{~s}(\nabla) \tau_{\mathrm{p}}=30 \mathrm{~s}(0)$. 


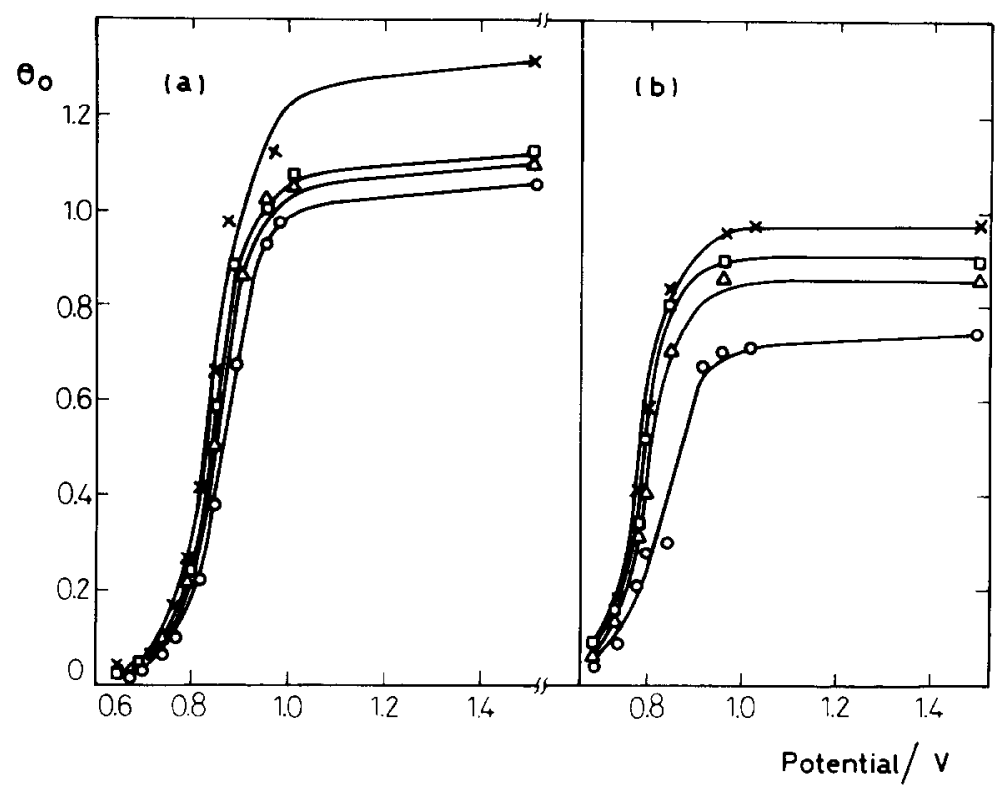

Fig. 8. Dependence of $\theta_{0}$ on the potential $E_{\mathrm{c}}$ at which the potential scan is applied after the open circuit potential decay from $E_{\mathrm{s}, \mathrm{a}}$ to $E_{\mathrm{e}}$, (a) $\mathrm{N}_{2}$ saturated, (b) $\mathrm{CO}$ saturated. $\tau_{\mathrm{p}}=0(\mathrm{O}) ; \tau_{\mathrm{p}}=5 \mathrm{~s}(\Delta) ; \tau_{\mathrm{p}}=1 \mathrm{~s}(\square)$ and $\tau_{\mathrm{p}}=30 \mathrm{~s}(\times)$.

curve implies, in principle, a quasi-equilibrium situation among the different adsorbed species. In carbon monoxide containing electrolyte under open circuit three different reactions contribute, in principle, to decrease the coverage by the O-electroadsorbed species on the polarized platinum electrode, namely, the corresponding chemical dissolution by the acid electrolyte itself, the possible corrosion-type reaction [17] and the reaction of carbon monoxide with O-adatoms. In any case, the adsorption of carbon monoxide takes place on the electrode surface which remains free.

The interpretation of the anodic potential decay under open circuit can be made in terms of a conventional equivalent circuit involving three parallel components, namely $C_{\mathrm{dl}}$, the double layer capacitance, $C_{\mathrm{ad}}$, the adsorption pseudocapacitance and $R_{\mathrm{F}}$, the resistance of the reaction involved in the decay process. At $E=E_{\mathrm{e}}$, the following relationship holds

$\tau\left(E_{\mathrm{e}}\right)=R_{\mathrm{F}}\left(C_{\mathrm{dl}}+C_{\mathrm{ad}}\right)=-E_{\mathrm{e}} /(\mathrm{d} E / \mathrm{d} t)_{E=E_{\mathrm{c}}}$

Providing the change with potential of $R_{\mathrm{F}}$ is smaller than that of the capacitive terms, the $\tau\left(E_{\mathrm{c}}\right)$ vs. potential plot can be interpreted as the capacitance/potential profile of the system. The diagram resulting in the absence of $\mathrm{CO}\left(\tau_{\mathrm{p}}=\mathrm{O}\right)$ coincides with that already reported by Schuldiner and Roe [13] (Fig. 9(a)), but that resulting in the presence of $\mathrm{CO}\left(\tau_{\mathrm{p}}=\mathrm{O}\right)$ involves considerable differences, such as the decrease in height and the shift of the pseudocapacitance peak related to O-electro- 
adsorption towards more negative potentials and the appearance of an apparent capacitive peak with a discontinuity at ca. $0.66 \mathrm{~V}$ (Fig. 9(b)). The characteristics of this peak resemble those already found during the adsorption of organic substances on mercury electrodes [18]. In the potential ranges where the capacitance remains practically constant lower pseudocapacitance values result in the presence of carbon monoxide (Fig. 9(c)). In principle, the capacitance discontinuity observed at ca. 0.66 $\mathrm{V}$ can be interpreted as a bidimensional rearrangement of the adsorbed $\mathrm{CO}$-species, probably related to an order-disorder transition [19] similar to that observed in the adsorption of both pyridine and aniline on mercury electrodes [20,21]. In these two cases the corresponding adsorption energy is mainly related to a potential dependent absorbate- $\pi$-electrons-metal interactions producing two different adsorbent-substrate structures.

In general, the adsorption of a molecule in two configurations ( 1 and 2$)$ is characterized by the corresponding standard free energy of adsorption as $\theta \rightarrow 0$, the specific substrate area per adsorbed molecule, the adsorption potential and limiting

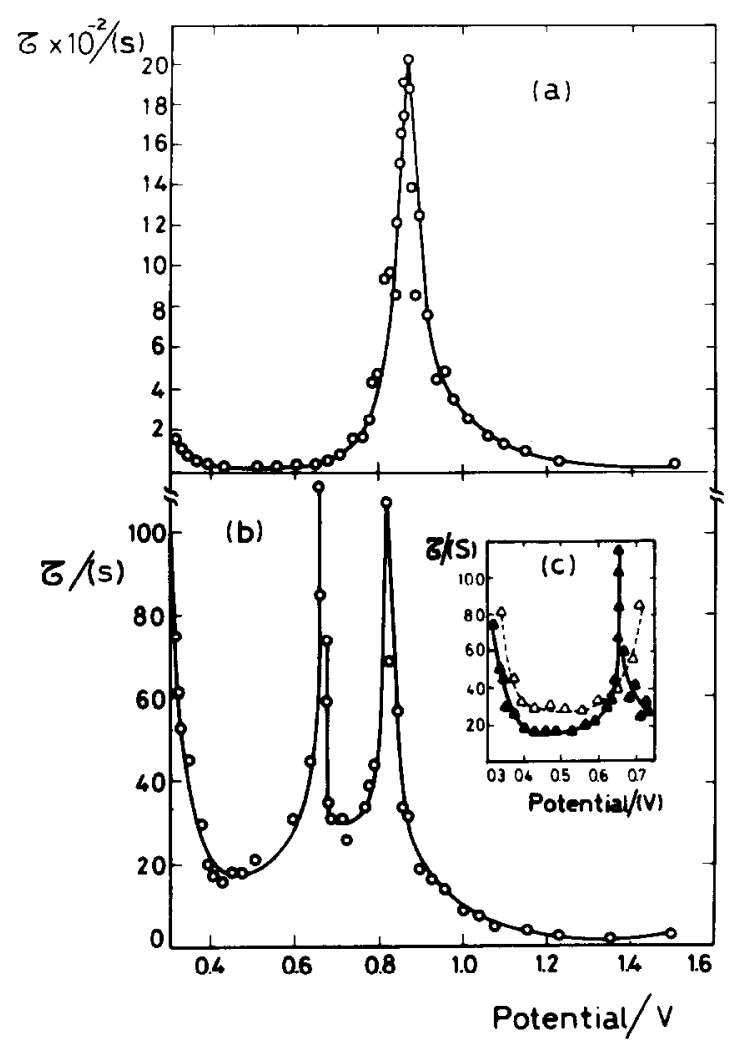

Fig. 9. Capacitance/potential plot obtained from the potential decay (Figs. 1 and 2 ), $\tau_{p}=0$. (a) $N_{2}$ saturated; (b) $\mathrm{CO}$ saturated interface; (c) comparison between (a) and (b) in the 0.3-0.7 $\mathrm{V}$ range. 
pseudocapacitance values [18]. In our case, configuration (1) can be assigned to bridge-type adsorbed carbon monoxide and prevails as $\theta \rightarrow 0$ while configuration (2), which can be related to linear adsorbed carbon monoxide, is attained as $0 \rightarrow 1$. The change from (1) to (2) implies a change in the net dipolar moment of the adsorbed molecule from zero to a small positive value [22]. For a system which can, in principle, be described by a Frumkin-type isotherm, the form of the latter, depending on the interaction parameter value, may present a region which is typical of transition phenomena [18]. In the case of the electroadsorption isotherm this is reflected in the $\theta / E$ plot through a potential range where for each value of $E$ there are three values of $\theta$. Consequently, as during the potential decay from the anodic potential side $(0.25 \mathrm{~V}<E<0.6 \mathrm{~V}) \mathrm{d} \theta / \mathrm{d} t$ for carbon monoxide adsorption is always positive, the sign of $\mathrm{d} E / \mathrm{d} t$ is determined by that of $\mathrm{d} E / \mathrm{d} \theta$. The interpretation of the maximum in Fig. 2 which has been previously reported by Stonehart [23], in terms of transition phenomena related to the bidimensional carbon monoxide adsorbed layer is also supported by the transients depicted in Fig. 3. In this case, the potential overshoot disappears, probably because the carbon monoxide coverage attained during the potential sweep up to $E_{\mathrm{s}}$ is outside the region of the electrochemical isotherm where the transition phenomena should occur.

The decrease of the $\mathrm{O}$-adatom coverage on anodized platinum under open circuit has already been studied both in acid electrolyte $[24,25]$ and in acid melt $[11,12]$ in the absence of carbon monoxide. The removal of oxygen atoms from the metal surface leaves a practically free metal surface which may become very active for the complementary anodic reaction involved in a corrosion-type mechanism such as that formally denoted by the following overall reactions:

cathodic reaction

$\mathrm{Pt}(\mathrm{O})+\mathrm{H}_{2} \mathrm{O}+2 e^{-}=\mathrm{Pt}+2 \mathrm{OH}^{-}$

anodic reactions

$$
\begin{aligned}
& \mathrm{Pt}=\mathrm{Pt}^{2+}+2 e^{-} \\
& \mathrm{H}_{2}=2 \mathrm{H}^{+}+2 e^{-} \\
& \mathrm{X}=\mathrm{X}^{n+}+n e^{-}
\end{aligned}
$$

Reaction (4a) was actually determined in the potential range associated with the potentiodynamic electroadsorption/electrodesorption of $\mathrm{H}$ - and $\mathrm{O}$-adatoms [26]. It contributes to the partial reforming of the electrode surface, changing the electrode roughness and the corresponding energy distribution at the metal surface [26]. Reaction (4b) takes into account the possible presence of traces of molecular hydrogen dissolved in the electrolyte and reaction (4c) denotes the possible impurity (X) electrooxidation. In any case, the rate of the kinetics of the anodic potential decay in the presence of carbon monoxide is considerably greater than in the absence of carbon monoxide. Hence the corresponding reaction mechanisms are, in principle, different.

Both the voltammograms and the rate of the potential decay at open circuit of anodized platinum in saturated carbon monoxide acid electrolyte should provide 
information about the reaction between carbon monoxide and electroadsorbed oxygen. These results can be interpreted on the basis of one of the following three reaction pathways.

\section{(i) Electrochemical mechanism}

This reaction pathway is, in certain ways, similar to that postulated for the reaction in the absence of carbon monoxide. It comprises the following cathodic and anodic reactions

$$
\begin{aligned}
& \mathrm{Pt}(\mathrm{O})+\mathrm{H}_{2} \mathrm{O}+2 e^{-}=\mathrm{Pt}+2 \mathrm{OH}^{-} \\
& \mathrm{CO}+\mathrm{H}_{2} \mathrm{O}=\mathrm{CO}_{2}+2 \mathrm{H}^{+}+2 e^{-}
\end{aligned}
$$

This mechanism predicts a linear $E / \log \left[\theta_{0} /\left(1-\theta_{0}\right)\right]$ relationship with a slope proportional to the ratio $R T / F$ and a linear dependence of the rate of change of the $\mathrm{O}$-adatom surface coverage with the corresponding degree of surface coverage. The experimental results do not fulfil these predictions. Otherwise, it seems rather unlikely that, within the $0.68-1.51 \mathrm{~V}$ potential range, reaction (6) occurs with no adsorption of reactants.

\section{(ii) Eley-Rideal-type thermal mechanism}

According to the ER mechanism for a thermal heterogeneous reaction a precursor carbon monoxide molecule, physically adsorbed, reacts with an $\mathrm{O}$-adatom yielding a carbon dioxide molecule and a free metal site as follows

$\mathrm{Pt}(\mathrm{O})+\mathrm{CO}=\mathrm{Pt}+\mathrm{CO}_{2}$

The corresponding rate equation is

$$
-\mathrm{d} \theta_{0} / \mathrm{d} t=k_{\mathrm{ER}} \theta_{\mathrm{O}}[\mathrm{CO}]
$$

where $k_{\mathrm{ER}}$ is the corresponding formal kinetic constant and [CO] is the concentration of carbon monoxide in the solution. Equation (8) also implies a first order rate law with respect to $\theta_{0}$, which is not observed.

\section{(iii) Langmuir-Hinshelwood-type thermal mechanism}

In this case the reaction which involves an adsorbed carbon monoxide molecule and an $\mathrm{O}$-adatom is represented by the equation

$\mathrm{Pt}(\mathrm{O})+\mathrm{Pt}(\mathrm{CO})=2 \mathrm{Pt}+\mathrm{CO}_{2}$

The main difference between reactions (7) and (9) lies in the greater bond strength between platinum and carbon monoxide in the latter as compared to the former. In this respect it is worthwhile to mention that data on the gas phase carbon monoxide adsorption on platinum [27-30] favour carbon monoxide chemisorption as a step preceding reaction (9).

The rate of $\mathrm{O}$-adatom disappearance $\left(-\mathrm{d} \theta_{0} / \mathrm{d} t\right)$ resulting from data shown in Fig. 7, plotted as a function of $\theta_{0}$ (Fig. 10) exhibits a maximum value in the intermediate range of $\theta_{0}$ and it becomes zero both as $\theta_{0} \rightarrow 0$ and $\theta_{0} \rightarrow 1$. The rate at the maximum increases according to $\tau_{\mathrm{p}}$ from ca. 0.3 to ca. 0.5 . These results suggest 
that the reaction of carbon monoxide with $\mathrm{O}$-adatoms is preceded by the adsorption of the former species. The initiation of the reaction becomes feasible because the maximum coverage by $\mathrm{O}$-adatoms attained at $E_{\mathrm{s}, \mathrm{a}}$ is less than a monolayer. This fact is consistent with data resulting from gas phase carbon monoxide adsorption on platinum [31] which indicates that even for a platinum surface saturated with O-adatoms there are still free sites for carbon monoxide adsorption. Furthermore, the initiation of the reaction may be assisted by both the surface heterogeneity of polycrystalline platinum and the small fraction of dermasorbed oxygen on platinum [12,32]. Therefore, the reaction pathway for the open circuit potential decay of anodized platinum in carbon monoxide containing acid electrolyte can be put as follows

$$
\mathrm{Pt}+\mathrm{CO} \stackrel{k}{\rightarrow} \mathrm{Pt}(\mathrm{CO})
$$

$\mathrm{Pt}(\mathrm{CO})+\mathrm{Pt}(\mathrm{O}) \stackrel{k_{1 . H}}{\rightarrow} 2 \mathrm{Pt}+\mathrm{CO}_{2}$

where $\operatorname{Pt}(\mathrm{CO})$ becomes an intermediate which can be detected on the electrode surface only for $\theta_{0}<0.05$ (Fig. 6) and $k_{\mathrm{CO}}$ and $k_{\mathrm{LH}}$ are the formal rate constants of reactions (10a) and (10b), respectively. The corresponding rate equations are

$\mathrm{d} \theta_{\mathrm{CO}} / \mathrm{d} t=k_{\mathrm{CO}}\left(1-\theta_{\mathrm{O}}-\theta_{\mathrm{CO}}\right)-k_{\mathrm{LH}} \theta_{\mathrm{O}} \theta_{\mathrm{CO}}$

$-\mathrm{d} \theta_{0} / \mathrm{d} t=k_{\mathrm{LH}} \theta_{\mathrm{O}} \theta_{\mathrm{CO}}$

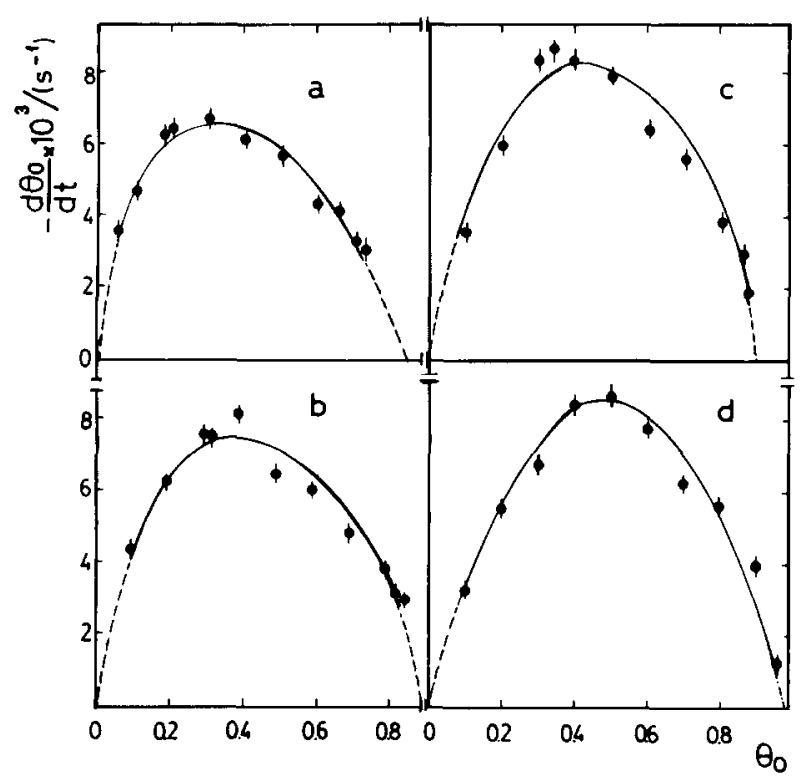

Fig. 10. Dependence of $\mathrm{d} \theta_{0} / \mathrm{d} t$ on $\theta_{0}$. Data taken from Fig. 7 (b). $\tau_{\mathrm{p}}=0$ (a); $\tau_{\mathrm{p}}=5 \mathrm{~s}(\mathrm{~h}) ; \tau_{\mathrm{p}}=15 \mathrm{~s}$ (c); $\tau_{\mathrm{p}}=30 \mathrm{~s}(\mathrm{~d})$. 
TABLE 1

Kinetic data

\begin{tabular}{lllll}
\hline$\tau_{\mathrm{p}} / \mathrm{s}$ & $k_{\mathrm{CO}} / \mathrm{s}^{-1}$ & $k_{\mathrm{LH}} / \mathrm{s}^{-1}$ & $\theta_{\mathrm{O}, \mathrm{M}}($ from Eqn. (15)) & $\theta_{\mathrm{O}, \mathrm{M}}($ from Fig. 10) \\
\hline 0 & $0.14 \pm 0.02$ & $0.9 \pm 0.1$ & 0.27 & $0.30 \pm 0.02$ \\
5 & $0.26 \pm 0.04$ & $0.56 \pm 0.08$ & 0.36 & $0.37 \pm 0.02$ \\
15 & $0.46 \pm 0.07$ & $0.46 \pm 0.07$ & 0.41 & $0.42 \pm 0.02$ \\
30 & $0.8 \pm 0.1$ & $0.42 \pm 0.06$ & 0.45 & $0.47 \pm 0.02$ \\
\hline
\end{tabular}

Assuming steady-state conditions for $\theta_{\mathrm{CO}}$ as occurs for $\theta_{0}>0.05$, it results in

$\theta_{\mathrm{CO}}=k_{\mathrm{CO}}\left(1-\theta_{\mathrm{O}}\right) /\left[k_{\mathrm{CO}}+k_{\mathrm{LH}} \theta_{\mathrm{O}}\right]$

Then, substituting eqn. (13) into eqn. (12), the rate of O-adatom disappearance becomes

$-\mathrm{d} \theta_{\mathrm{O}} / \mathrm{d} t=k_{\mathrm{LH}} k_{\mathrm{CO}} \theta_{\mathrm{O}}\left(1-\theta_{\mathrm{O}}\right) /\left[k_{\mathrm{CO}}+k_{\mathrm{LH}} \theta_{\mathrm{O}}\right]$

Equation (14) predicts a linear relationship between $\theta_{0}\left(1-\theta_{0}\right)\left(-\mathrm{d} \theta_{0} / \mathrm{d} t\right)^{-1}$ and $\theta_{0}$ which is satisfactorily fulfilled by the experimental data (Fig. 11). Correspondingly, the $k_{\mathrm{LH}}$ and $k_{\mathrm{CO}}$ values are estimated from the slopes of the straight lines and from extrapolation to $\theta_{0}=0$ (Table 1 ). The kinetic constants change according to the potentiostatic ageing time of $\mathrm{O}$-adatoms at the platinum surface. At the maxima of the plots shown in Fig. 10, the coverage by O-adatoms resulting from the corresponding second order equation, for $\theta>0$, becomes

$\theta_{\mathrm{O}, \mathrm{M}}=\left(k_{\mathrm{CO}} / k_{\mathrm{LH}}\right)\left[-1+\left(1+k_{\mathrm{LH}} / k_{\mathrm{CO}}\right)^{1 / 2}\right]$

The dependence of $\theta_{\mathrm{O} . \mathrm{M}}$ on $\tau_{\mathrm{p}}$ calculated from eqn. (15) (Table 1) is in agreement with the experimental data shown in Fig. 10.

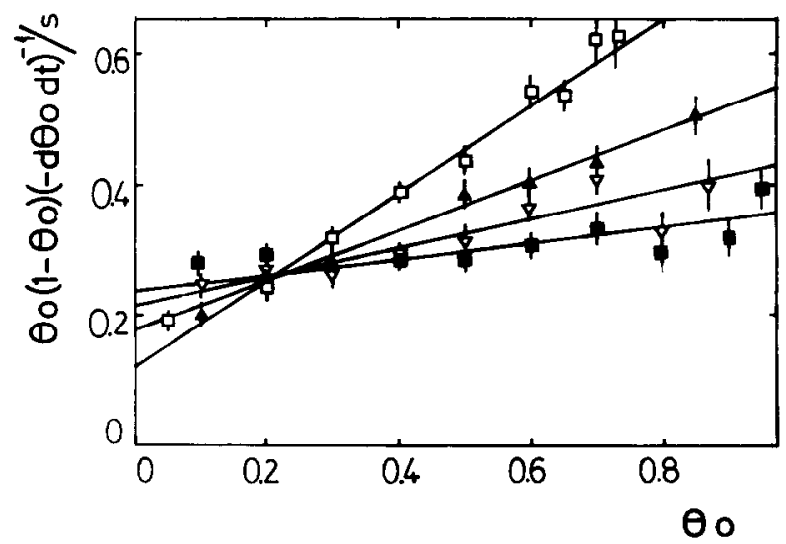

Fig. 11. Plot of eqn. (14). Data taken from Fig. 10. $\tau_{\mathrm{p}}=0(\square) ; \tau_{\mathrm{p}}=5 \mathrm{~s}(\Delta) ; \tau_{\mathrm{p}}=15 \mathrm{~s}(\nabla) ; \tau_{\mathrm{p}}=30 \mathrm{~s}(\mathbf{\square})$. 
Reaction (10b) implies a replacement of O-adatoms by adsorbed carbon monoxide so that the anodic potential decay involves a surface which is practically completely covered by adsorbed species. From the structural standpoint this means that only the linear adsorbed form of carbon monoxide should participate in the overall reaction. In agreement with this conclusion, the present results show no evidence of the bridge form of adsorbed carbon monoxide, as it appears, for instance, in the electrooxidation of carbon monoxide on polycrystalline platinum starting from carbon monoxide adsorption on a clean surface.

The increase of $k_{\text {co }}$ with $\tau_{\mathrm{p}}$ can be interpreted in terms of the increase of the $\mathrm{Pt}-\mathrm{O}$ bond energy produced through the ageing of the adsorbed $\mathrm{O}$-atom. The greater localization of electrons on the $\mathrm{O}$-adatom and the local electric field increase the heteropolar contribution to the $\mathrm{Pt}-\mathrm{O}$ bond. Hence, the lower electron density accomplished in the vicinity of $\mathrm{O}$-adatoms favours the $\mathrm{Pt}-\mathrm{CO}$ bond formation. This explanation is congruent with the fact that the adsorption of one species on a surface which is either partially or completely covered by another species may induce desorption energy changes of opposite sign for the pre-adsorbed species [33]. The reduction metal $\rightarrow 2 \pi^{*} \mathrm{CO}$ electron backdonation by the presence of electronegative ligands is a well-known effect in the chemistry of carbonyl complex compounds [34]. The same explanation extends to the decrease of $k_{\mathrm{LH}}$ with $\tau_{\mathrm{p}}$. In this case, however, the increment in the $\mathrm{Pt}-\mathrm{O}$ bond energy implies a greater energy to produce reaction $(10 \mathrm{~b})$, that is the rate of this reaction decrease.

\section{ACKNOWLEDGEMENT}

The INIFTA is sponsored by the Consejo Nacional de Investigaciones Cientificas y Técnicas, the Universidad Nacional de La Plata and the Comisión de Investigaciones Científicas (Provincia de Buenos Aires).

\section{REFERENCES}

1 J.P. Randin in A.J. Bard (Ed.), The Encyclopedia of Electrochemistry of the Elements, Vol. 7, Marcel Dekker, New York, 1976, p. 152.

2 M.W. Breiter, Electrochemical Processes in Fuel Cells, Springer Verlag, New York, 1969.

3 M.W. Breiter in J.O'M. Bockris and B.E. Conway (Eds.), Modern Aspects of Electrochemistry, Vol. 10, Plenum Press, New York, 1979, p. 161.

4 S. Gilman, J. Phys. Chem., 66 (1962) 2657; 67 (1963) 78; 67 (1963) 1898.

5 S.A. Bilmes, N.R. de Tacconi and A.J. Arvía, J. Electrochem. Soc., 127 (1980) 2184

6 S.A. Bilmes, N.R. de Tacconi and A.J. Arvía in W.E. O'Grady, P.N. Ross and F.G. Will (Eds.), Proc. Symp. on Electrocatalysis, Electrochem. Soc., 1982, p. 276.

7 S. Gilman, J. Phys. Chem., 68 (1964) 70.

8 P. Stonehart, Electrochim. Acta, 15 (1970) 1853; 18 (1973) 63; 18 (1973) 211.

9 S.A. Bilmes, N.R. de Tacconi and A.J. Arvia, J. Electroanal. Chem., 164 (1984) 129.

10 B. Beden, S. Bilmes, C. Lamy and J. M. Léger, J. Electroanal. Chem., 149 (1983) 295.

11 N.R. de Tacconi, A.J. Calandra and A.J. Arvia, J. Electroanal. Chem., 51 (1974) $25 ; 57$ (1974) 325.

12 M.E. Folquer, N.R. Tacconi and A.J. Arvía, J. Electrochem. Soc., 130 (1983) 622.

13 S. Schuldiner and R.M. Roe, J. Electrochem. Soc., 110 (1963) 332; 110 (1963) 1142. 
14 V.S. Bagotzkii, Yu.B. Vassilyev, J. Weber and J.N. Pirtshalava, J. Electroanal. Chem., 22 (1970) 31.

15 A.J. Arvia, Isr. J. Chem., 18 (1979) 89.

16 F.G. Will, J. Electrochem. Soc., 112 (1965) 451.

17 M.M. Lohrengel and J.W. Schultze, Electrochim. Acta, 21 (1976) 951.

18 B.B. Damaskin, O.A. Petrii and V.V. Batrakov, Adsorption of Organic Compounds on Electrodes, Plenum Press, New York, 1971, p. 11.

19 A.N. Frumkin, Z. Phys. Chem., 116 (1925) 466.

20 L.D. Klyukina and B.B. Damaskin, Izv. Akad. Nauk USSR., (1963) 1022.

21 B.B. Damaskin, I.P. Mishutushkina, V.M. Gerovich and R.I. Kaganovich, Zh. Fis. Khim., 38 (1964) 1797.

22 P.R. Norton, J.W. Goodale and E.B. Selkirk, Surf. Sci., 83 (1979) 189.

23 P. Stonehart in D.M. Collins (Ed.), Proc. 5th Int. Symp. on Power Sources, Brighton, Pergamon Press, Oxford, 1967 p. 509.

24 F. Barz and M. Lungu, J. Electroanal. Chem., 133 (1982) 101.

25 A. Hoffman and A.T. Kuhn, Electrochim. Acta, 9 (1964) 835.

26 D.A.J. Rand and R. Woods, J. Electroanal. Chem., 35 (1972) 209; C.D. Pallotta, N.R. de Tacconi and A.J. Arvia, Electrochim. Acta, 26 (1981) 261; A.E. Bolzan, M.E. Martins and A.J. Arvia, J. Electroanal. Chem., 157 (1983) 339.

27 C.T. Campbell, G. Ertl. H. Kuipers and J. Segner, J. Chem. Phys., 73 (1980) 5862.

28 J.R. Creighton, F.H. Tseng, J.M. White and J.S. Turner, J. Chem. Phys., 85 (1981) 703.

29 M.A. Barteau, E.I. Ko and R.J. Madix, Surf. Sci., 104 (1981) 161.

30 H. Okamoto, G. Kawamura and T. Kudo, J. Catal., 82 (1983) 332.

31 P.R. Norton, D.K. Creber and J.W. Goodale in G. Ertl (Ed.), Proc. 4th Int. Conf. on Solid Surf. and 3rd Eur. Conf. on Surf. Sci., Cannes, 1980.

32 S. Schuldiner and T.B. Warner, J. Electrochem. Soc., 112 (1965) 212, 853.

33 G. Ertl in T.N. Rhodin and G. Ertl (Eds.), The nature of the Surface Chemical Bond, North Holland, Amsterdam, 1979, p. 367.

34 T.L. Brown and D.J. Darensbourg, Inorg. Chem., 6 (1967) 971. 